\title{
Investigation on Influence of Aspect Ratio of Micro dimples on Coefficient of Friction of Lubricated Sliding Surfaces in Boundary Lubrication
}

\author{
Rasal Shraddhesh ${ }^{\dagger}$, V.N.V Aravind ${ }^{\dagger}$, Pakala Pradeep $^{\dagger}$ and P M Anil ${ }^{+*}$ \\ †School of Mechanical and Building Sciences, VIT University, Vellore, Tamil Nadu, India \\ Accepted 02 Sept 2016, Available online 05 Sept 2016, Vol.6, No.5 (Oct 2016)
}

\begin{abstract}
This paper deals with the study of the influence of aspect ratio on coefficient of friction of lubricated reciprocating surfaces in boundary lubrication regime. Experiments were carried out on high frequency reciprocating wear testing machine. The operating conditions were set such that the boundary lubrication regime is achieved. Area density of $10 \%$ and dimple depth of $25 \mu \mathrm{m}$ maintained for all the samples. Results obtained in the tests showed that there exists an optimum value aspect ratio for which minimum value of friction coefficient is achieved. The trend of variation of friction coefficient can be explained by considering degree of interference of pressure generated at adjacent dimples and oil supply capabilities of surface textures. The value of coefficient of friction for untextured specimen was found to be lower than that of textured specimens.
\end{abstract}

Keywords: Laser surface texturing, Aspect ratio, Area density, Boundary lubrication.

\section{Introduction}

The analysis of the engine friction distribution shows that piston assembly (50\%) and journal bearings $(10 \%)$ have high share in the frictional power of an engine. Recently, surface texturing technique has emerged as an option for improvement in coefficient of friction, wear resistance, load capacity etc. The dimples can serve as micro-hydro dynamic bearing in case of full and mixed lubrication, enhancing load support and increasing film thickness, which leads to lower friction compared to untextured surfaces. Also they act as reservoir for lubricant in cases of starved conditions and micro trap for wear debris.

Considerable amount of research work is being carried out in this area, which includes study of various texturing techniques like etching techniques, ion beam texturing and laser surface texturing. Of all the techniques laser surface texturing (LST) is the most promising technique because of its precise control over shape and size of dimples and fast operation (Etsion et al., 2001).

Recent research has considered optimization of micro-dimples for automotive components including bearings and piston rings and most of the studies are based on experimental analysis.

Simulations are done on parameters such as area ratio and diameter of dimple. Optimum parameters

*P M Anil is working as Asst. Prof. (S.G.) were found in the range of $20-30 \%$ area ratio and diameter of the dimple $100-200 \mu \mathrm{m}, 80 \%$ less friction is obtained compared with untextured surface in hydro dynamic lubrication (Ramesh et al.,2013).

Surface texturing of the block surface (area density between 20 \& 26\%) resulted in significant improvement in wear resistance in comparison to a system with an untextured block. Extensive literature survey revealed that usually dimple depth over dimple diameter ratio ranging from $0.01-0.3$ and area density up to $30 \%$ exist for assemblies operated in lubricated sliding condition (Pawlus et al.,2007).

(Beomkeun Kim, et al. ) studied effect of variation of aspect ratio and area density of hemispherical dimples and found that optimum behavior was achieved for aspect ratio of 0.14 and $10 \%$ surface area density, also the effect of aspect ratio was found to be more significant on frictional characteristics as compared to surface area density (Kim et al.,2014).

Effect of variation in depth of micro dimples was studied by (Scaraggi, et al. )who found that their exist optimum value of depth where minimum co-efficient of friction is obtained .Depth of $3.9 \mu \mathrm{m}$ (for diameter of $100 \mu \mathrm{m}$ ) and $3.7 \mu \mathrm{m}$ (for diameter of $50 \mu \mathrm{m}$ ) (Galda et $a l, 2005)$.

(Costa, et al.) carried out test on lubricated reciprocating surfaces with various shapes and orientations of dimples, they found that the effect of surface texturing is maximum in elasto-hydro dynamic regime maximum oil film thickness was achieved at 
maximum speed and minimum at reversal points (Michele Scaraggi et al., 2014).

Wei Tang et al. studied effect of surface texturing and lubricated steel surfaces with various surface area ratios, aspect ratios and found that $5 \%$ area density ratio and 0.1 aspect ratio provides best results (Wei Tang et al.,2013).

Literature review shows significant variation in optimum results (i.e. aspect ratio: 0.039 to 0.335 and area ratio: 5 to $30 \%$ ). Hence there must exists some co-relation between optimum values of area ratio and aspect ratio. The aim of this study is to find the effect of variation of aspect ratio alone on frictional characteristics in boundary regime with automotive applications into considerations.

\section{Methodology}

\subsection{Material}

Material used for the test was Chromalloy EN 24(AISI 4340). Even though cast iron is most commonly used material for piston rings, EN 24 was selected so as to eliminate additional lubricating effects caused due to the presence of graphite in cast iron. Graphite acts as a solid lubricant and also has a tendency to act as reservoir for lubricant in oil starvation conditions (Wei Tang et al.,2013).

\subsection{Test rig}

Reciprocating wear testing was selected as a method to examine the frictional characteristics of the specimens, so as to simulate reciprocating wear occurring in automobile applications such as piston rings. It is accomplished by using High frequency reciprocating wear test machine which is equipped with data acquisition and control system. The test apparatus consist of upper specimen sliding over the lower specimen with constant stroke length. The upper specimen is clamped in a holder which is mounted on a reciprocating arm while lower specimen is held in its place using fixture. The drive consists of an electric motor with $1 \mathrm{~kW}$ power output which rotates the cam so as to impart motion to the reciprocating arm. The frequency of operation can be varied in range of 10 to $15 \mathrm{~Hz}$ and average sliding speed can calculated as,

$\mathrm{V}=2 \mathrm{~nL}(1)$

Where, V - Average sliding velocity (m/s)

$\mathrm{n}$ - frequency of operation $(\mathrm{Hz})$

$\mathrm{L}$ - Stroke length (m)

The machine is provided with facility of setting load, temperature of lubricant, frequency and duration of test. Also it is provided with a load sensor to measure frictional force and LVRT sensor to measure wear depth.

A pin of diameter $10 \mathrm{~mm}$ was used as upper specimen while lower specimen consisted of rectangular block of dimensions $30 \mathrm{~mm} \mathrm{X} 30 \mathrm{~mm} \mathrm{X}$
$10 \mathrm{~mm}$. Surface texturing was done on top face of lower specimen. This pin and flat surface type arrangement was used to simulate operating conditions of piston rings so as to ensure complete conformity, as it is found that achieving complete conformity is difficult in case of ring and liner type arrangement of reciprocating wear test. Texturing was carried out on the lower specimen.

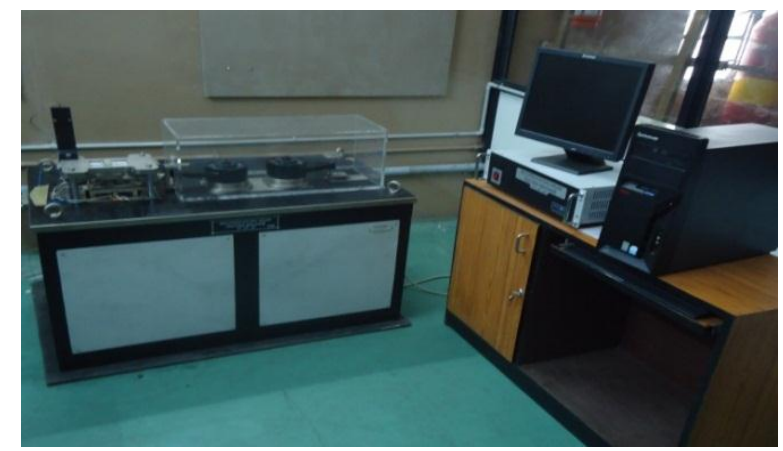

Fig.1 High frequency reciprocating wear test machine

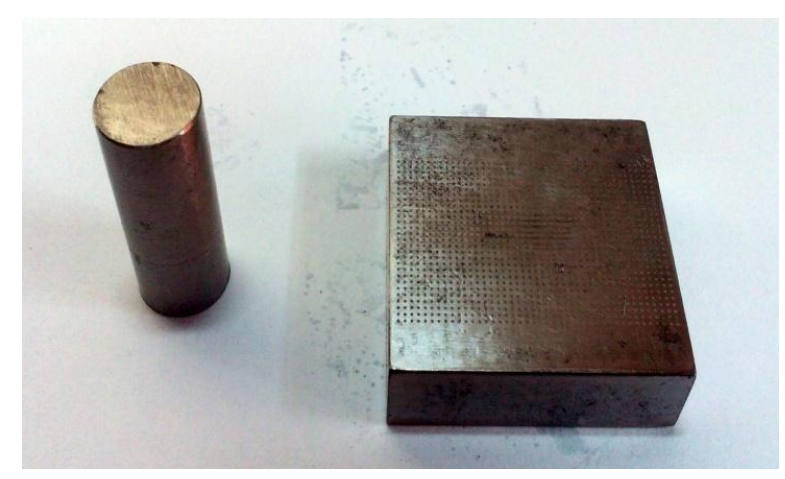

Fig 2. Pin and rectangular block specimen

\subsection{Texturing Parameters}

Dimensions of the dimples were selected so as to make all other parameters except aspect ratio to be constant. Area ratio is maintained constant at $10 \%$ and depth at $25 \mu \mathrm{m}$.

Table 1. Texturing Parameters of Samples

\begin{tabular}{|c|c|c|c|}
\hline $\begin{array}{c}\text { Sample } \\
\text { No. }\end{array}$ & $\begin{array}{c}\text { Aspect } \\
\text { ratio }\end{array}$ & $\begin{array}{c}\text { Dimple Dia. } \\
(\mu \mathrm{m})\end{array}$ & $\begin{array}{c}\text { Centre } \\
\text { Distance }(\mu \mathrm{m})\end{array}$ \\
\hline 0 & - & 0 (Untextured) & - \\
\hline 1 & 0.05 & 500.00 & 1401.52 \\
\hline 2 & 0.1 & 250.00 & 700.76 \\
\hline 3 & 0.15 & 166.67 & 467.17 \\
\hline 4 & 0.20 & 125.00 & 350.38 \\
\hline 5 & 0.25 & 100.00 & 280.30 \\
\hline
\end{tabular}

\subsection{Sample Preparation}

Raw materials used for preparation of pin and rectangular block were circular rod with diameter 15 $\mathrm{mm}$ and flat plate with rectangular cross-section of 
$35 \mathrm{~mm}$ X $15 \mathrm{~mm}$ both made of EN 24. Wire EDM process was used to obtain specimens with required dimensions. Heat treatment was carried out by Hardening at the temperature of $950^{\circ} \mathrm{C}$ followed by tempering at $150^{\circ} \mathrm{C}$. Final surface finish was obtained by grinding operation followed by surface polishing using grade 800 emery sheet. Surface texturing on the samples is carried out using Laser Surface Texturing technique, because of its fast operation and precise control over its dimensional accuracy.

\subsection{Operating Conditions:}

Operating conditions were maintained constant for all the specimens so as to achieve boundary lubrication regime.

Table 2. Operating Conditions

\begin{tabular}{|c|c|}
\hline Parameter & Value \\
\hline Frequency & $10 \mathrm{~Hz}$ \\
\hline Average Sliding Velocity & $0.3 \mathrm{~m} / \mathrm{s}$ \\
\hline Load & $20 \mathrm{~N}$ \\
\hline Duration & $120 \mathrm{~min}$. \\
\hline Lubricant & SAE 30 \\
\hline Temperature & Room Temp. \\
\hline
\end{tabular}

\section{Results and Discussion}

Coefficient of friction shows significant reduction during initial part of the test, as expected because of the running in condition. Trend is seen clearly in Fig.3 provided in Appendix. Specimens 2 and 3 show slight deviation from general tendency of running in condition which remain unexplained with current available data. Gradually, the coefficient of friction stabilizes and all the samples show almost constant coefficient of friction in last 40 minutes of the test. Table 2 shows average coefficient of friction during last 40 min of test.

Table 3. Average Coefficient of friction

\begin{tabular}{|c|c|c|}
\hline Sample & Aspect ratio & $\begin{array}{c}\text { Average coefficient of } \\
\text { friction }\end{array}$ \\
\hline 0 & - & 0.129 \\
\hline 1 & 0.25 & 0.181 \\
\hline 2 & 0.2 & 0.1549 \\
\hline 3 & 0.15 & 0.1632 \\
\hline 4 & 0.1 & 0.1659 \\
\hline 5 & 0.05 & 0.2098 \\
\hline
\end{tabular}

Average values of Coefficient of Friction decrease from sample 1 to 2 and then increases from samples 2 to 5 . The increase in coefficient of friction is less from samples 2 to 4 but the last sample shows significant increase in coefficient of friction.

Untextured sample shows lower coefficient of friction than the all the textured samples showing that surface texturing doesn't improve frictional characteristics when operating under boundary lubricated regime, which is similar to the results obtained in previous study[0 Ajayi et al., 2011]

The results are in conformity with the study carried out by X wang et al.[ Peter Andersson, 2001] which studied the variation in load carrying capacity of textured surface with dimple diameter at constant area density.

This increase in coefficient of friction from samples 2 to 5 may be because of decrease in overall pressure with decreasing aspect ratio due to reduced interference between adjacent dimples[X Wang et al., 2003]. Also it supports the mechanism of reduction of oil supply with increasing distance between the adjacent dimples (i.e. decreasing aspect ratio)[ Aviram Ronen et al., 2001]. The mechanism behind the increase of coefficient of friction for sample 1 is still unclear and requires further investigation.

\section{Conclusion}

From the results obtained by tests carried out we can conclude that there exist optimum value of aspect ratio for which we can obtain minimum coefficient of friction. Reduction in the interference between adjacent dimples and reduced oil supply can be considered as the reason for increase in the coefficient of friction for low values of aspect ratio. Also it can be inferred from the results that surface texturing do not improve frictional characteristics under boundary lubrication regime.

\section{References}

Etsion I, Chapter (2001) 13 , Tribology and dynamics of engine and powertrain ,PP 458-460.

Ashwin Ramesh et al., (2013) Friction characteristics of microtextured surfaces under mixed and hydrodynamic lubrication, Tribology International 57 170-176.

Pawel Pawlus et al., (2007) The effect of oil pockets size and distribution on wear in lubricated sliding, Wear 2631585 1592.

Beomkeun Kim et al.,(2014) Effects of surface texturing on the frictional behavior of cast iron surfaces, Tribology International70, 128-135.

Lidia Galda et al,(2005) Dimples shape and distribution effect on characteristics of Stribeck curve.

Michele Scaraggi et al., (2014) Minimize friction of lubricated laser microtextured surfaces by tuning microholes depth, Tribology International 75,123-127

Wei Tang et al., The effect of surface texturing on reducing the friction and wear of steel under lubricated sliding contact, Applied Surface Science 273 (2013) 199- 204.

Peter Andersson,(2001) Piston Ring Tribology -a literature survey , VTT Tiedotteita - Research notes 2178

$\mathrm{X}$ Wang et al., Loads carrying capacity map for the surface texture design of $\mathrm{SiC}$ thrust bearing sliding in water, Tribology International 36 (2003) 189-197.

Aviram Ronen et al., Friction Reducing Surface texturing in automotive components, Tribology International ,44,(2001), 3 359-366.

$\mathrm{X}$ wang et al. Optimization of the surface texture for silicon carbide sliding in water, Applied Surface Science 253 (2006) 1282-1286.0

Ajayi et al., Friction and wear behavior of laser textured surface under lubricated initial point contact, Wear 271 (2011) 17191725 


\section{Appendix}

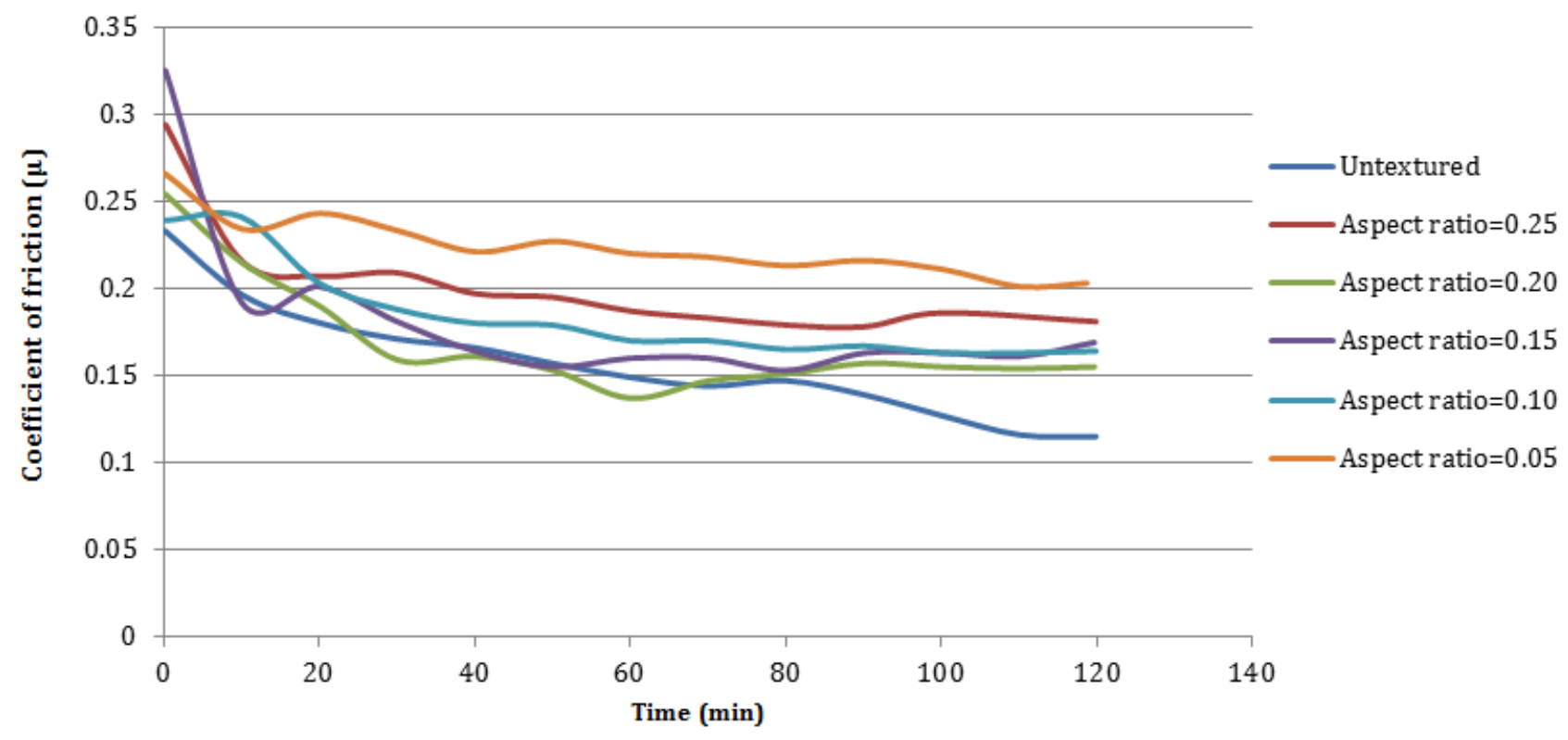

Fig.3 Graph of coefficient of friction v/s Time 